\title{
COMPARISON BETWEEN THERAPEUTIC ULTRASOUND AND SCAR MOBILIZATION OVER PERSISTENT POSTNATAL DYSPAREUNIA
}

\author{
MARIYAM FARZANA SF ${ }^{1}$, PONMATHI P ${ }^{2 *}$, SIVAKUMAR VPR \\ ${ }^{1}$ Department of Physiotherapy, SRM College of Physiotherapy, SRM University, Kattankulathur, Kanchipuram, Tamil Nadu, India. \\ ${ }^{2}$ Department of Physiotherapy, SRM University, Kattankulathur, Kanchipuram, Tamil Nadu, India. Email: ponmathi_sugadev@yahoo.co.uk
}

Received: 29 March 2017, Revised and Accepted: 19 May 2017

\section{ABSTRACT}

Objective: Dyspareunia is known as the painful sexual intercourse. This study was conducted to compare the effectiveness between therapeutic ultrasound and scar mobilization in persistent postnatal dyspareunia.

Methods: This is an experimental study. 30 subjects with superficial dyspareunia, age group between 25 and 35 years are taken in this study and 15 subjects in Group A were treated with ultrasound therapy, 15 subjects in Group B were treated with scar mobilization. Female sexual functional index questionnaire (FSFI) and visual analogue scale (VAS) were used as the outcome measure.

Results: Results showed a significant difference in FSFI and VAS measurements in both the groups, but clinically Group A showed better improvement in pain and quality of life than Group B.

Conclusion: There is no significant difference between ultrasound therapy and scar mobilization over the pain and quality of life in patients with persistent postnatal dyspareunia.

Keywords: Pelvic floor muscles, Superficial dyspareunia, Female index sexual questionnaire, Ultrasound therapy, Scar mobilization.

(C) 2017 The Authors. Published by Innovare Academic Sciences Pvt Ltd. This is an open access article under the CC BY license (http://creativecommons. org/licenses/by/4. 0/) DOI: http://dx.doi.org/10.22159/ajpcr.2017.v10i9.18757

\section{INTRODUCTION}

Labor is the culmination of gestation period with the birth of one or more newborn infants. There are three stages of labor, stage one is the shortening and dilation of the cervix, stage two constitutes descent and birth of the infant, whereas stage three ends with birth of the placenta. Delivery may lead to overstretching of the vagina, causing tears in the perineal tissue between the vagina and rectum.

Perineal tear classification is a system used to quantify the severity of trauma to the perineum during vaginal childbirth. Lacerations are classified into four categories: First degree tear: Laceration is limited to the fourchette and superficial perineal skin or vaginal mucosa. Second degree tear: Laceration extends beyond fourchette, perineal skin and vaginal mucosa to perineal muscles and fascia, but not the anal sphincter. Third degree tear: Fourchette, perineal skin, vaginal mucosa, muscles, and anal sphincter are torn. Fourth degree tear: Fourchette, perineal skin, vaginal mucosa, muscles, anal sphincter, and rectal muscosa are torn.

Episiotomy is a surgical scar made in the perineum of gravida in the late second stage of labor to widen introitus and straighten the lower end of the birth canal. It also helps in avoiding inappropriate natural perineal tear that may involve anal sphincter and rectum. Episiotomy is classified into three types; they are midline episiotomy, mediolateral, and hockey stick episiotomy. Factors strongly associated with both the severity and rate of postpartum Dyspareunia are the type and degree of perineal injury and adherent scar of episiotomy. Researches found that women who delivered with an intact perineum reported the best outcomes in terms of sexual function and pain [1].

Nociceptive pain is protective and is a normal response to tissue injury in comparison to that neuropathic pain is a pathologic or maladaptive pain, results from damage to the nervous system, producing pain in the absence of stimulation of nociceptors or inappropriate response to stimulation of nociceptors [2].
Etiology of dyspareunia following childbirth can be physical or psychological, or a combination of both. Physical or organic superficial dyspareunia can be secondary to scar tissue formation, poor anatomical reconstruction following perineal trauma or vaginal dryness. Adhesion of perineal scars can cause pain with intercourse.

The prevalence of dyspareunia is difficult to estimate following childbirth as many women with persistent symptoms do not seek medical attention. Furthermore, when comparing to the findings of research studies, higher prevalence rate was $62 \%$ of women in the study experienced dyspareunia during the first three postpartum months [3]

Dyspareunia is a common problem after labor, which may persist for months and even years. It often remains untreated because formal postnatal care has been completed by the time it becomes persistent problem. When treatment is given, it usually consists of reassurance sometimes combined with symptomatic lubricant, or local anesthetic, ointment or cream $[4,5]$. It affects the sexual quality of life and makes the women depressed.

For so many years, therapeutic ultrasound is widely used in physiotherapy to treat soft tissue injuries, a lot of research support this. The first known trail report for the ultrasound therapy for the relief of pain on the episiotomy incision was published in the year 1979 [7] following which the effect of pulsed ultrasound over episiotomy was published in the year 1980 [6-9].

Scar mobilization lengthens connective tissue and scar adhesion, allowing fascia layers to slide easily over one another. It has been used by a lot of physiotherapist to mobilize the scars from its adherence to its underlying structures.

Physiotherapy in dyspareunia is a area where there is a want of more research to find the efficiency of each treatment available and to know the better treatment for the benefit of the patient. Hence, many studies 
have done on the effect of ultrasound on postnatal perineal pain [10] and dyspareunia [11].

But only negligible number of studies was done on scar mobilization, and no studies were so far done to compare the effect of ultrasound and scar mobilization over the dyspareunia and also least importance were given on sexual quality of life in early researches. Hence, the aim of this study is to compare the effectiveness of therapeutic ultrasound and scar mobilization among persistent postnatal dyspareunia patients using the outcome measures of pain and sexual quality of life.

\section{METHODS}

\section{Study design and sample}

This is an experimental, comparative type study done in SRM Medical College Hospital and Research Centre, Kattankulathur, Kanchipuram District, India, and New Life Hospital, East Tambaram, Chennai, India. 30 subjects diagnosed with superficial dyspareunia were conveniently selected and explained clearly about the procedure and written informed consent was taken and explained them the whole information obtained from them will be kept confidential.

Subjects with age between 25 to 35 years, with dyspareunia for the past 2 months, were included in the study. Subjects who were pregnant, with current vaginal infection or urinary tract infection, any gynecological surgery after the delivery or under psychiatry management and subjects with vaginismus were excluded from the study.

The subjects were assessed before the study for the details of parity, age, type of birth. Before providing the questionnaire, they were explained in detail about the study and the questionnaire. Pretest for the subjects was done with VAS and female sexual index questionnaire which was given to the subjects and explained and were asked to fill.

Then, the study population was divided into two groups conveniently, Group A subjects were allotted with the treatment of ultrasound therapy and Group B subjects were allotted with the treatment of scar mobilization.

\section{Procedure}

Group A subjects who were treated with ultrasound underwent the following procedure. Position of the patient is side lying with lower leg straight and upper leg bent up and supported with pillow. The head of the ultrasound is covered with a condom, gel is applied inside and outside of the condom, and the treatment is given directly over the episiotomy area. The parameters are frequency of $3 \mathrm{MHz}$, at an intensity of $0.5 \mathrm{~W} / \mathrm{cm}^{2}$ with $1: 1$ pulse interval. The duration of treatment is about 5 minutes for each session, 3 times a week and a total of eight sessions as a whole.

Group B subjects who were treated with scar mobilization underwent following procedure. Position of the patient is crook lying on the bed with legs abducted. Physiotherapist should use the gloved index finger and thumb, apply downward pressure on the posterior wall and then maintain the downward pressure for 1-3 minutes. Then, begin the gentle oscillation in all directions for 3 minutes, 3 times a week for 3 weeks.

All the subjects of Groups A and B were asked not to indulge in intercourse during the course of the study. Once when the full treatment session was over the female sexual functional index questionnaire (FSFI) [12] was given and was asked to fill again VAS score [13] were taken as a post-test results.

\section{RESULTS}

From the 45 subjects analyzed, there is no dropout and all 30 subjects were taken with post-test assessment. The pre- and post-test of pain and quality of life among Group A subjects were tabulated in Table 1. There was a statistical difference between pre- and post-test visual analog scale (VAS) readings in Group A subjects treated with therapeutic ultrasound $\mathrm{p}<0.05$; mean of VAS score before the treatment with ultrasound was 7.267 which was reduced significantly to mean of 5.867 after ultrasound treatment, difference between the mean is 1.38 , and there was a statistical difference between pre-test and post FSFI questionnaire readings in Group A subjects treated with ultrasound $\mathrm{p}<0.05$; mean of FSFI questionnaire score before the treatment with ultrasound was 22.387 which was reduced significantly to mean of 21.649 after ultrasound, difference between the mean is 0.738 .

Pre- and post-test of pain and quality of life among Group B subjects were tabulated in Table 2. There was a statistical difference between pre-test and post VAS readings in Group B subjects treated with scar mobilization $\mathrm{p}<0.05$; mean of VAS score before scar mobilization was 6.80 which was reduced significantly to mean 5.80 after scar mobilization, difference between the mean is 1 and there was a statistical difference between pre-test and post FSFI questionnaire readings in Group B subjects treated with scar mobilization $\mathrm{p}<0.001$; mean of FSFI questionnaire score before scar mobilization was 21.33 which was reduced significantly to mean 20.420 after scar mobilization, difference between the mean is 0.963 .

Post-test values of VAS and FSFI were compared between both the groups in Graph 1, which shows the post-test mean value of VAS in Group A (5.867) and Group B is (5.8) which shows that there was no

Table 1: Pre- and post-test values of VAS and FSFI questionnaire among Group A subjects treated with therapeutic ultrasound $(n=15)$

\begin{tabular}{lllll}
\hline $\begin{array}{l}\text { Outcome } \\
\text { measures }\end{array}$ & Mean \pm SD & & \multirow{2}{*}{ t-test } & \multirow{2}{*}{ Sig. } \\
\cline { 2 - 3 } & Pretest & Post-test & & \\
\hline VAS & $7.267 \pm 0.594$ & $5.867 \pm 0.640$ & 6.210 & 0.0000 \\
FSFI & $22.387 \pm 0.739$ & $21.647 \pm 0.657$ & 2.898 & 0.0072 \\
\hline
\end{tabular}

SD: Standard deviation, VAS: Visual analog scale, FSFI: Female sexual functional index

Table 2: Pre- and post-test values of VAS and FSFI questionnaire among Group B subjects treated with scar mobilization

\begin{tabular}{lllll}
\hline $\begin{array}{l}\text { Outcome } \\
\text { measures }\end{array}$ & Mean \pm SD & & \multirow{2}{*}{ t-test } & \multirow{2}{*}{ Sig. } \\
\cline { 2 - 3 } & Pretest & Post-test & & \\
\hline VAS & $6.80 \pm 0.775$ & $5.80 \pm 0.775$ & 3.534 & 0.0014 \\
FSFI & $21.333 \pm 0.910$ & $20.420 \pm 0.973$ & 2.654 & 0.0130 \\
\hline
\end{tabular}

SD: Standard deviation, VAS: Visual analog scale, FSFI: Female sexual functional index

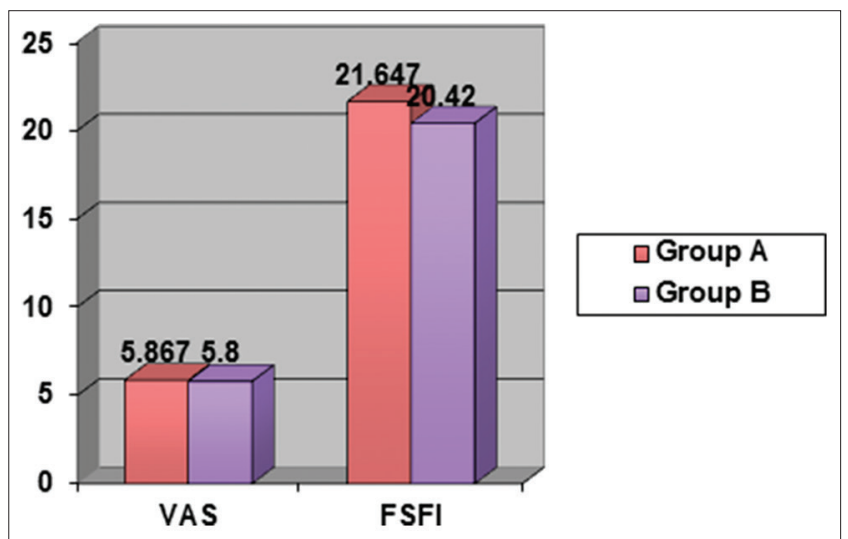

Graph 1: Comparison of post-test measures of visual analogue scale scores and female sexual functional index questionnaire scores between Group A subjects treated with ultrasound and Group B subjects treated with scar mobilization 
significant difference between both the groups. This Graph 1 also shows the post-test mean value of FSFI in Group A (21.6) and Group B is (20.4) which infers again that there is no significant difference between both the groups.

\section{DISCUSSION}

This study is focused on comparing the effect of ultrasound and scar mobilization on superficial dyspareunia. Episiotomy may sometimes get healed with getting adherent with the underlying structures which left untreated becomes persistent problem leading to superficial dyspareunia.

But in India, many women do not speak on their sexual life and do not come out when they have a dyspareunia which is distressing and post a challenge to women's health physiotherapist. Furthermore, the awareness of physiotherapy management for the same is neglected among physiotherapist in India and gynaecologists. Research on this field is also very minimal to support and define the best Physiotherapy management for the benefit of the patients. Hence, this study demands the need of the hour.

Valadares et al. found that there was a prevalence of about $35.9 \%$ of sexual dysfunction among Brazilian middle-aged women [14]. However, no study exist on the sexual dysfunction prevailing in Indian population, this study found about 30 patients with superficial dyspareunia. Further studies should be done to document the various sexual dysfunction prevailing among Indian women.

A lot of studies had focused on the dyspareunia in immediate postnatal perineal pain and found the effects of ultrasound therapy, pulsed electromagnetic therapy and found its effect on quality of life and pain [15-19]. However, only very few studies had found the effect of ultrasound therapy over the complicated episiotomy scar and no studies had compared scar mobilization and ultrasound over superficial dyspareunia.

Dyspareunia is more prevalent after vaginal birth, and this was supported by Signorello who concluded that among post-partum females $41 \%$ and $22 \%$, respectively, reported dyspareunia even after a period of 6 months and they all had given vaginal birth [20].

The statistical results of this study show that there is a significant difference in pain ratings measured by VAS and FSFI questionnaire post-treatment with ultrasound $(\mathrm{p}<0.05)$.

Theoretical understanding of therapeutic ultrasound effects suggests that pain is decreased as the resolution of the inflammatory process accelerated and compression of pain sensitive structures by hematoma and oedema is reduced.

Increased vascularity at the wound site is a good sign because it further favors the tissue remodeling [21]. Ultrasound increases the blood flow to the target area which helps in tissue repair and remodeling.

This was supported by Dyson 1987 who concluded that ultrasound has a better effect on tissue repair and pain relief in soft tissue injuries [22].

The statistical results of this study show that there is a significant difference in pain ratings measured by VAS and FSFI questionnaire post-treatment with scar mobilization $(\mathrm{p}<0.05)$.

Adhesion of perineal scars can cause pain with intercourse. The effect of scar mobilization is to lengthen connective tissue and scar adhesion, allowing fascia layers to slide easily over one another $[23,24]$.

This goes in hand with Christine Kettle, Kahled Ismail et al. 2005 - who suggested that the women who massaged the area of scar tissue with good quality of oil postnatally tends to have a reduction of tenderness and pain during penetration in sexual intercourse [3].
But on comparing both the groups, from the statistical analysis, it was found from this study that there was no statistically significant difference between both the groups. Clinically subjects showed a better feedback on reduction of pain and quality of life postultrasound management than scar mobilization. This may be due to the lack of long-term follow-up and small sample size. Further researches should be targeted with large sample size and on the subjects who had more than one episiotomy.

So according to the results, ultrasound has clinically better effect in reducing in pain and improving sexual function in postpartum dyspareunia patients as scar mobilization.

\section{CONCLUSION}

This study concludes that ultrasound therapy, scar mobilization both show a statistically significant result in reduction of pain and improvement in sexual function in subjects with superficial dyspareunia. However, there was no significant difference between ultrasound and scar mobilization over pain and sexual function in subjects with superficial dyspareunia. Both ultrasound and scar mobilization can be recommended for the benefit of the patient with dyspareunia.

\section{REFERENCES}

1. Glazener CM, Abdalla M, Stroud P, Naji S, Templeton A, Russell IT. Postnatal maternal morbidity: Extent, causes, prevention and treatment. Br J Obstet Gynaecol 1995;102(4):282-7.

2. Thakur S, Srivastava N. An update on neuropathic pain models. Int J Pharm Pharm Sci 2016;8(6):11-6.

3. Kettle C, Ismail KM, O'Mahony F. Dyspareunia following childbirth. Obstet Gynaecol 2005;7(4):245-9.

4. Grant A, Sleep J, McIntosh J, Ashurst H. Ultrasound and pulsed electromagnetic energy treatment for perineal trauma. A randomized placebo-controlled trial. Br J Obstet Gynaecol 1989;96(4):434-9.

5. Sleep J, Grant A, Garcia J, Elbourne D, Spencer J, Chalmers I. West Berkshire perineal management trial. Br Med J (Clin Res Ed) 1984;289(6445):587-90.

6. Binder A, Hodge G, Greenwood AM, Hazleman BL, Page Thomas DP. Is therapeutic ultrasound effective in treating soft tissue lesions? $\mathrm{Br}$ Med J (Clin Res Ed) 1985;290(6467):512-4.

7. Fieldhouse C. Ultrasound for relief of painful episiotomy scars. Physiotherapy 1979;65(7):217.

8. Foulkes J. The application of therapeutic pulsed ultrasound to the traumatised perineum. Br J Clin Pract 1980;34(4):114-7.

9. Haar GT, Dyson M, Oakley S. Ultrasound in physiotherapy in the United Kingdom: Results of a questionnaire. Physiother Pract 1988;4(2):69-72

10. Hashish I, Hai HK, Harvey W, Feinmann C, Harris M. Reduction of postoperative pain and swelling by ultrasound treatment: A placebo effect. Pain 1988;33:303-11.

11. Everett T, McIntosh J, Grant A. Ultrasound therapy for persistent postnatal perineal pain and dyspareunia: A randomised placebo-controlled trial. Physiotherapy 1992;78(4):263-7.

12. Glazener C. Sexual function after childbirth: Women's experiences, persistent morbidity and lack of professional recognition. Int J Obstet Gynaecol 1997;104(3):330-5.

13. Carlsson AM. Assessment of chronic pain. I. Aspects of the reliability and validity of the visual analogue scale. Pain 1983;16(1):87-101.

14. Valadares AL, Pinto-Neto AM, Conde DM, Sousa MH, Osis MJ, CostaPaiva L. A population-based study of dyspareunia in a cohort of middleaged Brazilian women. Menopause 2008;15(6):1184-90.

15. Hay-Smith EJ. Therapeutic ultrasound for postpartum perineal pain and dyspareunia. Cochrane Database Syst Rev 2000;2:CD000495.

16. Sleep J, Grant A. West Berkshire perineal management trial: Three year follow up. Br Med J (Clin Res Ed) 1987;295(6601):749-51.

17. Everett T, McIntosh J, Grant A. Ultrasound therapy for persistent postnatal perineal pain and dyspareunia: A randomised placebo-controlled trial. Physiotherapy 1992;78(4):263-7.

18. McClaren J. Randomized controlled trial of ultrasound therapy for the damaged perineum. Clin Phys Physiol Meas 1984;5(1):40-4.

19. Schultz WC, van de Wiel HB, Heidemann R, Aarnoudse JG, Huisjes HJ. Perineal pain and dyspareunia after uncomplicated primiparous delivery. J Psychosom Obstet Gynecol 1990;11(2):119-27.

20. Signorello LB, Harlow BL, Chekos AK, Repke JT. Postpartum sexual 
functioning and its relationship to perineal trauma: A retrospective cohort study of primiparous women. Am J Obstet Gynecol 2001;184(5):881-8.

21. Kotian SR, Pai KS, Nayak JK, Bangera H, Prasad K, Bhat KM. Biomechanical, biochemical and histological evidences for wound healing properties of Indian traditional medicines. Int J Pharm Pharm Sci 2015;7(11):163-71
22. Young SR, Dyson M. The effect of therapeutic ultrasound on angiogenesis. Ultrasound Med Biol 1990;16:261-9.

23. Ombregt L. Deep Transverse Massage. Available from: http://www. ombregt.be.

24. Scar Management, OTR Therapy Skill Builders; 1998. Available from: http://www.harcourtassessment.com. 